\title{
EXTRACURRICULAR SPORT ACTIVITIES AND INSTITUTIONALIZED CHILDREN. SOCIALIZATION EFFECTS
}

\author{
Mariana Angelcheva
}

\begin{abstract}
Summary
The research paper aims to estimate the impact of extracurricular sport activities at the level of socialization in respect to children deprived of parental care.152 institutionalized children have been included in the respondent group, age from 8 to 14, in three age subgroups and two categories - sport involved and sport non-involved. The data obtained tell us that involvement in such activities significantly increases the child's socialization in respect to factors as social activity, personal autonomy and social adaptation. On the other hand, however, their effects on the children's ethic value system and behavior are very low.
\end{abstract}

Key words: extracurricular sport activities, socialization, children deprived of parental care.

\section{Introduction}

After the enforcement of the Child Protection Law (2000), the Bulgarian politics was directed to de-institutionalization of the children deprived of parental care and so, giving them a chance to live and to be educated in out-institution environment. This concentrates the state efforts and public attention on children social adaptation, carefully considering the values they have adopted in the special social institutions, on the one hand, and on the other, the requirements of the out-institution environment. The adaptation effects depend on the level of sufficiency between the individual perception of the personal Self and his/her social communications. A successful adaptation presupposes child adaptation to the bigger social community and, at the same time, creation of a capacity to establish stable own grounds while managing positively to survive everyday clashes.

The adoption of social roles gives each individual the chance to develop the personal Self and to become a real holistic personality. The difficulties, connected with the socialization process in the group of the children deprived of parental care, are usually associated with the barriers which they should surmount mastering some social roles. The lack of normal communication, typical for the other children (with a family, friends, relatives, etc.), creates a perception that the notion about such roles is developed on the ground of conflicting information coming from various socializing sources. It causes various troubles during the moral and emotional-determined development of the child as a person; the situation is typical for the age under discussion.

Both, the motive activity and the sport, establish a complex mechanism, a combination of biological, psychological and social effects on the physical organism and the personality, simultaneously. The sport as an extracurricular activity assists the child to form skills and habits, improves the health status and the physical Self-acceptation (Weiss \& Duncan, 1992), helps to set up higher Self-esteem, Self-respect, Self-confidence and Self-perfection (Iannotti R. et al., Group HPAF, 2005), to aspire to a better own psychological state (Kirkcaldy et al., 2002; Marsh,1998), more positive peer relations (Smith,1999) and less emotions linked to loneliness (Page et al., 1992), as well as socialization improvement and facilitation (Vilhjaimsson \& Kristjansdottir, 2003; Moore et al., 1991; Sallis et al., 1998).

In this country we do not have any specialized studies concerning socialization sport activity effects on the social growth of the institutionalized children.

\section{Aim and Objectives of the study}

The research goal was to estimate the impact of the extracurricular sport activities the socialization of children deprived of parental care. 152 children took part in the fieldwork as respondents; their age was from 8 to 14 years; they were of both genders (90 boys and 62 girls), and were divided in 3 age subgroups: a) 8-10; b) 11-12; and c) 13-14. As for the sports being extracurricular sport activities factor, the children were divided in two groups: a) sport-involved and b) sport non-involved. 


\section{Methods}

To make clear how the extracurricular sport activities effects surmount the institutional reactive behavioral model and what is the kind of connectivity between them and the socialization effects in children deprived of parental care-group, we have used the M. Rozhkov Scale. It enabled us to record the effects of social adaptation, social activity, autonomy and morals. The questionnaire included 20 statements evaluated on a 5 -degrees scale: 4 - always; 3 - almost always; 2 - occasionally; 1 - very rare; 0 never. Due to the values obtained for the coefficient factor, we could define the personal socialization level in each area, respectively: a) $>3$ - high level; b) between 2 и 3 - mean level; c) $<2$ - low level. These levels were set after an analysis of the fieldwork data. In order to calculate the medial values and standard deviations we used standard statistic methods.

\section{Results}

The adopted skills reflect the social adaptation level and include: a) acceptance of the rules and conformity to requirements imposed by the elders (teachers, educators, supervisors and parents while visiting the child in the institution); b) efforts to behave so that to get some credit; c) efforts to build up friendly and amicable peer relations; d) efforts to behave as all others. Such a behavior expresses a good-will to be accepted by those around you and readiness to obey the norm-frame set by the community. This means ambition for Self-control, respect for the elders' authority, conscientious and friendly mood to peers.

Such skills assimilation helps the child to develop adequate behavioral models; it guarantees emotional comfort for the grow-ups and enjoyment and satisfaction from the intercommunication with the environment as well as easy and graceful adaptation to it. The results for the social adaptation of sport-involved and non-involved institutionalized boys and girls are presented bellow in Figure 1.

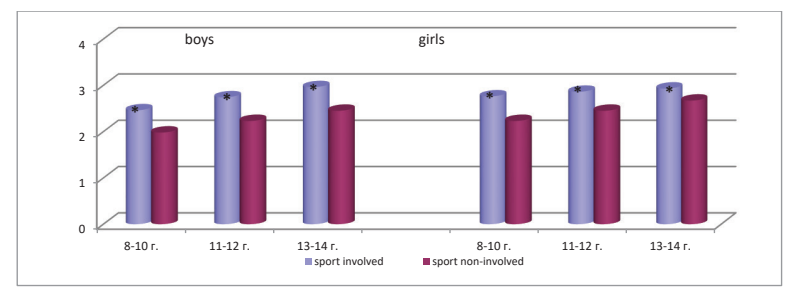

Figure 1. Data for social adaptation of sport involved and non-involved boys and girls from institutions (M. Rozhkov)

* Availability of statistically considerable distinction between the groups at $\alpha<0,05$.
The results of the sport-involved boys from all age groups are higher in comparison to sport-non-involved. However, the data obtained in the group of the sport-non-involved boys from the first subgroup are low. In the next two subgroups the social adaptation level, expectedly, grows but still remains lower than the sport active grow-ups, as the data obtained demonstrate.

This trend is preserved in the girls' group. However, the social adaptation in this group also does not go beyond above the mean level, irrespectively of the higher results. At the same time the data for the sport non-active young register levels closer to middle and downward to low levels.

Sport is a stimulation factor for the development of social qualities such as respect to elders, self-control and tolerance to others, Self-discipline and respect for sport rules. It is a guarantee for the greater social adaptation. On the other hand, the group activities create environment to build friendly peer relationships and they occur to be an important component in the social adaptation process.

Typical for the transition years of adolescence is the drive to autonomy, Self-esteem, Self-reliance and Self-confidence in the bigger community. According to T. Savova (2006), the institutionalized children rank autonomy at the lowest level in comparison to their peers from a natural family environment where the motivation to be independent is among the leading factors for personal development. Life in institutions supposes a low level of empathy. This deficit, namely, is the ground of the need for care and protection they are searching from the others. At the same time, the atmosphere in such institutions does not stimulate the otherness, does not tolerate being different, neither give a chance to be such; it does not create surroundings where individuality may develop.

Sports, especially the so-called individual ones, grant a new social environment; they create conditions to develop skills such as competitive spirit, leadership, Self-reliance and positive esteem that stimulate autonomy in the grow-ups group (Figure 2).

Again the sport-involved grow-ups from all age subgroups express higher opinion than sport non-involved. In the boys age-group, as a whole, the distinctions are higher than in the girls age- 
group. Therefore, the sport as a development factor influencing the formation of an independent autonomous personality is of higher value for the boys. Growing up, the non-involved from both gender groups begin perceiving autonomy as a more important factor; however, it still remains in the frame-limits between low and mean. One reason for such results may come from the specificity of the exercised sports; they are mostly individual ones - horse riding, swimming, tracks-and-fieldsathletics, and gymnastics.

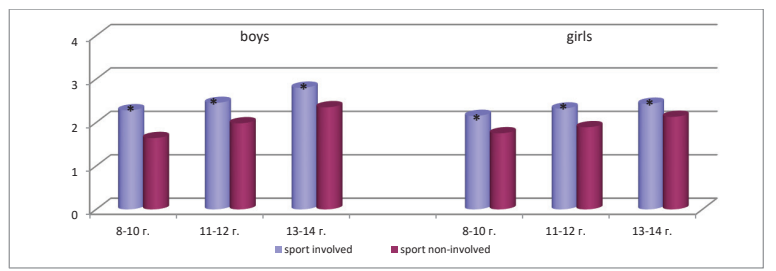

Figure 2. Data for autonomy of the sport involved and non-involved boys and girls from institutions (M. Rozhkov)

* Availability of statistically considerable distance between the groups at $\alpha<0,05$

Social activity is evaluated by studying: a) the ability to be successful in various initiatives; b) to have enough confidence while defending your own justice; c) the capacity to realize practically any ideas; d) the drive to be victorious; e) the know-how to carry through a particular initiative. Analysis shows (Figure 3) that the sportive boys from all age-groups evaluate social activity higher.

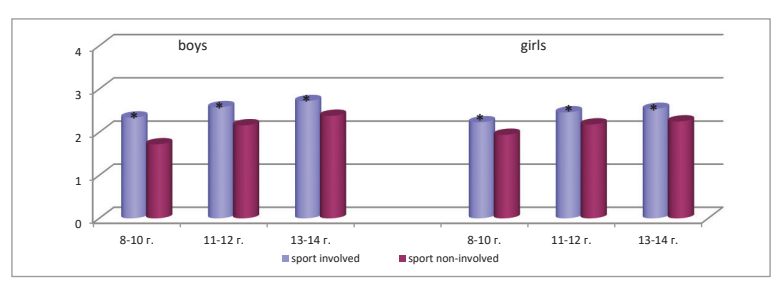

Figure 3. Data for social activity of sport involved and non-involved boys and girls from institutions (M. Rozhkov)

* Availability of statistically considerable distance between the groups at $a<0,05$

With age, social activity goes up in the group of sport non-involved children deprived of parental care; however, in this category it remains in the diapason of low to mean levels. In the group of the sport active children it is at medial level and drifts up. Similar results are got in the total girls' agegroup: the distinction here between sport active and non-active is smaller but considerable. The development dynamics in the various age subgroups of sport non-involved boys is similar to the dynamics of the boys non-involved in any sport; and with age its values again are going up from low to mean level but not beyond. Even though the results of the sport involved girls are a little bit higher, they still remain in the norms of the middle phase.

Good socialization presupposes higher morals, i.e. building up capability to be amicable, willing to help the other, empathic to their problems, endeavorable to protect the offended (Figure 4).

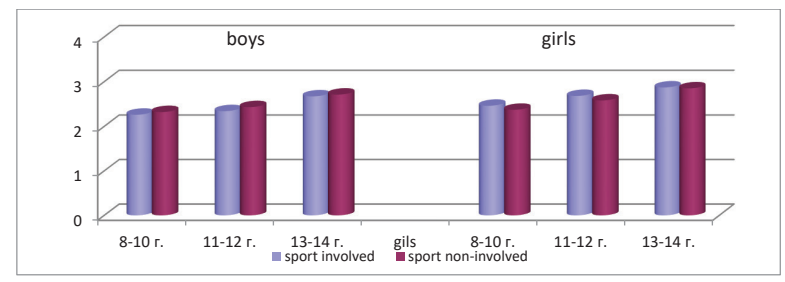

Figure 4. Data for morals of the sport involved and non-involved boys and girls from institutions (M. Rozhkov)

Absence of family or any important person in child's life is a serious reason for the institutionalized children deprived of parental care not to be able to build up simple social behavior models. The lack of empathy in their emotional relations with the stuff taking formal care for them, which, by the way, is frequently changed by the management, makes emotional and moral troubles in their individual development.

This explains, to some extent, why the effect of 'participation in extracurricular sport activities' is weaker evaluating the morals. Both genders do not endure any essential changes with age and the distinctions between sport non-involved and sport-involved is insignificant but in favor of the latter. Notwithstanding the small distance in all age/gender subgroups the expressed opinions remain in the frame of the mean phase. Therefore, the extracurricular sport activities have a real effect on the moral aspect of socialization.

\section{Discussion:}

The data obtained for the socialization evaluation opinion of the children deprived of parental care demonstrate that participation in extracurricular sport activities has a significant socializing effect in regard to social activity, autonomy and social adaptation. In all age/gender groups sport involving demonstrates mean socialization effect in comparison to sport non-engaged (in this group it is 
closer to the mean-low). In respect to morals, the evaluation opinion distinctions for both groups are insignificant and remain in the frame of the mean scores.

Participation in extracurricular sport activities stimulates the institutionalized boys and girls to develop social skills to respect elders (trainers), Self-control and behavioral tolerance, Self-discipline and respect to the established rules and norms, amicable peer relationships. So, they ensure higher socialization effect among sport active teenagers. Still these activities are not enough to overpass the sequences of the institutionalization and to achieve real high socialization effects.

\section{References:}

Iannotti R., Janssen I., Haug E., Kololo H., Annaheim B., Borraccino A., (2005), Group HPAF: Interrelationships of adolescent physical activity, screen-based sedentary behaviour, and social and psychological health. International Journal of Public Health.; 54(Suppl 2): pp.191-198.

Kirkcaldy B., Shephard R., Siefen R., (2002), The relationship between physical activity and self-image and problem behaviour among adolescents. Social Psychiatry and Psychiatric Epidemiology:; 37: pp.544-550.

Marsh H., (1998), Age and gender effects in physical self-concepts for adolescent elite athletes and non-athletes: A multicohort-multioccasion design. Journal of Sport and Exercise Psychology.; 20: pp.237-259.

Moore L., Lombardi D., White M., Campbell J., Oliveria S., Ellison R., (1991), Influence of parents' physical activity levels on activity levels of young children., Journal of
Pediatrics.; 118: pp.215-219.

Page R., Frey J., Talbert R., Falk C., (1992), Children’s feelings of loneliness and social dissatisfaction: Relationship to measures of physical fitness and activity. Journal of Physics Teacher Education; 11: pp.211-219.

Sallis J., Patterson T., Buono M., Atkins C., Nader P., (1998), Aggregation of physical activity habits in Mexican-American and Anglo families. Journal of Behavioral Medicine, 11: pp.31-41.

Savova, T., (2006), State and Development of the Need-Motivation Sphere of the Institutionalized Children Deprived of Parental Care, Author's essay, Shoumen, Bulgaria

Smith A., (1999), Perceptions of peer relationships and physical activity participation in early adolescence. Journal of Sport and Exercise Psychology; 21: pp.329-350.

Vilhjalmsson R., Kristjansdottir G., (2003), Gender differences in physical activity in older children and adolescents: the central role of organized sport. Social Science \& Medicine.; 56: pp.363-374.

Weiss M., Duncan S., (1992), The relationship between physical competence and peer acceptance in the context of children's sports participation. Journal of Sport and Exercise Psychology; 14: pp.177-191.

Research Methodology in Socialization of Pupils' Personality, as to M. Rozhkov http://www.vashpsixolog. ru/psychodiagnostic-school-psychologist/69-diagnosis-emotional-and-the-personal-sphere/1351-metodika-dlya-izucheniya-soczializirovannosti-lichnostiuchashhegosy(accessed December 2012).

* Mariana Angelcheva MD, PhD, National Sport Academy "Vassil Levski", Ass. Prof. at Department of Kinesitherapy and Rehabilitation; address: 1, Gurguljat Street, 1117 Sofia; Bulgaria; +359889008269; e-mail: angelcheva dr@abv.bg 